\title{
Bax and the mitochondrial permeability transition cooperate in the release of cytochrome $c$ during endoplasmic reticulum-stress-induced apoptosis
}

\author{
D Zhang ${ }^{1}$ and JS Armstrong ${ }^{*, 1}$
}

Endoplasmic reticulum (ER) stress induces apoptosis by mechanisms that are not fully clear. Here we show that ER stress induced by the $\mathrm{Ca}^{2+}$-ATPase inhibitor thapsigargin (THG) activates cytochrome $c$-dependent apoptosis through cooperation between Bax and the mitochondrial permeability transition (MPT) in human leukemic CEM cells. Pharmacological inhibition of the MPT as well as small interfering RNA (siRNA) knockdown of the MPT core component cyclophilin D blocked cytochrome $c$ release and caspase-dependent apoptosis but did not prevent Bax activation, translocation or $\mathrm{N}$-terminal exposure in mitochondria. siRNA knockdown of Bax also blocked THG-mediated cytochrome $c$ release and apoptosis, but did not prevent MPT activation and resulted in caspase-independent cell death. Our results show that ER-stress-induced cell death involves a caspase and Bax-dependent pathway as well as a caspase-independent MPT-directed pathway.

Cell Death and Differentiation (2007) 14, 703-715. doi:10.1038/sj.cdd.4402072; published online 15 December 2006

The endoplasmic reticulum $(E R)$ regulates protein synthesis and intracellular calcium $\left(\mathrm{Ca}^{2+}\right)$ homeostasis. ${ }^{1}$ Excessive ER stress can trigger apoptosis through a variety of mechanisms including redox imbalance, alterations in $\mathrm{Ca}^{2+}$ levels and activation of Bcl-2 family proteins. ${ }^{2,3}$ Thapsigargin (THG), a sesquiterpenoid plant alkaloid, is frequently used to study the mechanisms regulating ER-stress-induced apoptosis and has previously been found to induce apoptosis in cancer cell lines via activation of the death receptor pathway and the mitochondrial pathway. 2,3

The mitochondrial apoptotic signalling pathway involves activation of the proapoptotic Bcl-2 family member Bax, which induces permeabilization of the mitochondrial outer membrane and release of cytochrome $c .^{4-6}$ The mechanism(s) regulating Bax activation and translocation to mitochondria are incompletely understood, but its integration into the mitochondrial outer membrane appears to depend on a conformational change that exposes the $\mathrm{N}$-terminus of the protein on the membrane surface, whereas its C-terminus facilitates membrane insertion. ${ }^{7}$ In the outer membrane, Bax undergoes oligomerization to form a pore that facilitates the release of cytochrome $c$. $^{8,9}$ However, in addition to Bax, other key events are required to cause the complete release of cytochrome $c$ from mitochondria including disruption of cytochrome $c$ from the electron transport chain (ETC), ${ }^{10,11}$ structural changes to the mitochondrial cristae inner membrane ${ }^{12,13}$ and the activation of the mitochondrial permeability transition (MPT). ${ }^{14,15}$

The role of the MPT in apoptosis has recently been challenged by the observation that cells, isolated from genetically modified mice, lacking the MPT core component cyclophilin D (Cyp-D) were not protected from Bcl-2 family member regulated cell death suggesting that the MPT does not play a major role in apoptosis. ${ }^{16,17}$ However, this idea contrasts previous reports showing that $\mathrm{Bcl}-2$ family proteins, including Bax, interact with components of the MPT including the adenine nucleotide translocator (ANT) and the voltagedependent anion channel (VDAC) to regulate apoptosis. ${ }^{18-21}$ These controversies prompted us to investigate the role of the MPT and Bax in ER-stress-induced apoptosis.

In this study, we used small interfering RNA (siRNA) technology to investigate the role of the MPT and Bax in apoptosis induced by ER stress. Our results suggest that, in addition to Bax, calcium-dependent mitochondrial changes, including activation of the MPT, are crucial for the successful release of cytochrome $c$ and induction of apoptosis by ER stress.

\section{Results}

THG treatment induces cytosolic and mitochondrial $\mathrm{Ca}^{2+}$ increase in CEM cells. Figure 1A shows results of an immunoblot for Cyp-D protein expression after transfection with control siRNA (left) and Cyp-D siRNA (right). Right lane shows $\sim 90 \%$ decrease in Cyp-D protein after transfection with Cyp-D siRNA compared to control. Figure 1B, left captions show FACS analysis histograms of Fluo3-AM-stained CEM cells before and after treatment with either $\mathrm{THG} \pm$ ruthenium 360 (Ru360), siRNA knockdown of Cyp-D or cyclosporin A (CsA). Thin black trace (control); heavy black trace (THG) and heavy green trace (a) THG + Ru360, (b) THG + Cyp-D siRNA treatment and (c)

\footnotetext{
'Department of Biochemistry, Yong Loo Lin School of Medicine, National University of Singapore, Singapore, Republic of Singapore

*Corresponding author: JS Armstrong, Department of Biochemistry, Yong Loo Lin School of Medicine, National University of Singapore, 8 Medical Drive, Singapore, Republic of Singapore. Tel: + 656516 5996; Fax: + 656779 1453; E-mail: bchisa @nus.edu.sg

Keywords: apoptosis; mitochondria; Bax; mitochondrial permeability transition; cyclosporin $A$; cyclophilin $D$

Abbreviations: THG, thapsigargin; MPT, mitochondrial permeability transition; CsA, cyclosporin A; Cyp-D, cyclophilin D; siRNA, small interfering RNA; ANT, adenine nucleotide translocator; TEM, transmission electron microscopy; ETC, electron transport chain; CJ, contact junction; SE, standard error of the mean

Received 22.6.06; revised 30.10.06; accepted 30.10.06; Edited by M Piacentini; published online 15.12.06
} 
A

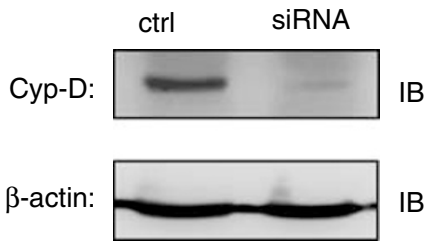

B

Cytosolic calcium

Mitochondrial calcium (Fluo3 fluorescence)

(Rhod2 fluorescence)

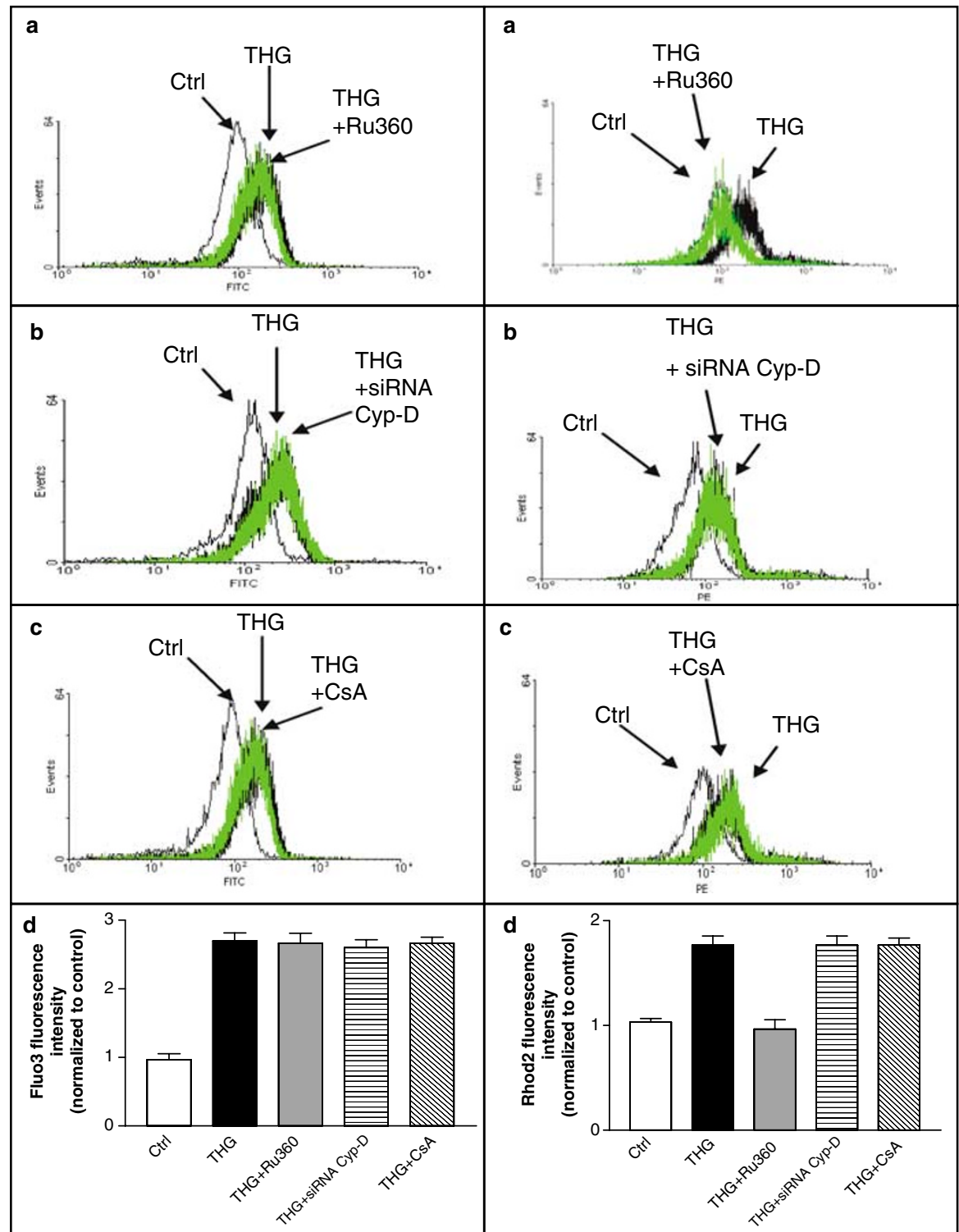

Figure 1 (A) Results of an immunoblot of Cyp-D protein expression in CEM cells after transfection with control siRNA (left) and Cyp-D siRNA (right) performed as described under 'Materials and Methods'. (B) Cytosolic calcium panel: representative FACS analysis histograms of Fluo3-AM-stained CEM cells treated with THG \pm (a) Ru360, (b) Cyp-D siRNA and (c) CsA. Thin black trace: control; heavy black trace: THG; heavy green trace: THG + respective treatment. Panel d shows bar graph of cytosolic calcium levels (mean \pm S.E) expressed as mean Fluo3 fluorescence intensity normalized to control. The cells were loaded with $1 \mu \mathrm{M}$ Fluo3-AM for 15 min and the green fluorescence was immediately measured by flow cytometry using the FITC setting as described under 'Materials and Methods'. In each analysis, 10000 events were recorded. Mitochondrial calcium panel: representative FACS analysis histograms of Rhod2-AM-stained CEM cells treated with THG \pm (a) Ru360, (b) Cyp-D siRNA and (c) CsA. Thin black trace: control; heavy black trace: THG; heavy green trace: THG + respective treatment. Panel (d) shows bar graph of mitochondrial calcium levels (mean \pm S.E) expressed as mean Rhod2 fluorescence intensity normalized to control. The cells were loaded with $250 \mathrm{nM}$ Rhod 2-AM for 15 min and the red fluorescence was immediately measured by flow cytometry using the PE setting as described under 'Materials and Methods' In each analysis, 10000 events were recorded. (C) Figure shows representative confocal images of CEM cells loaded with DAPI, MitoTracker green and Rhod2-AM after treatment with THG or THG + Ru360 as described in the Materials and Methods section 
C
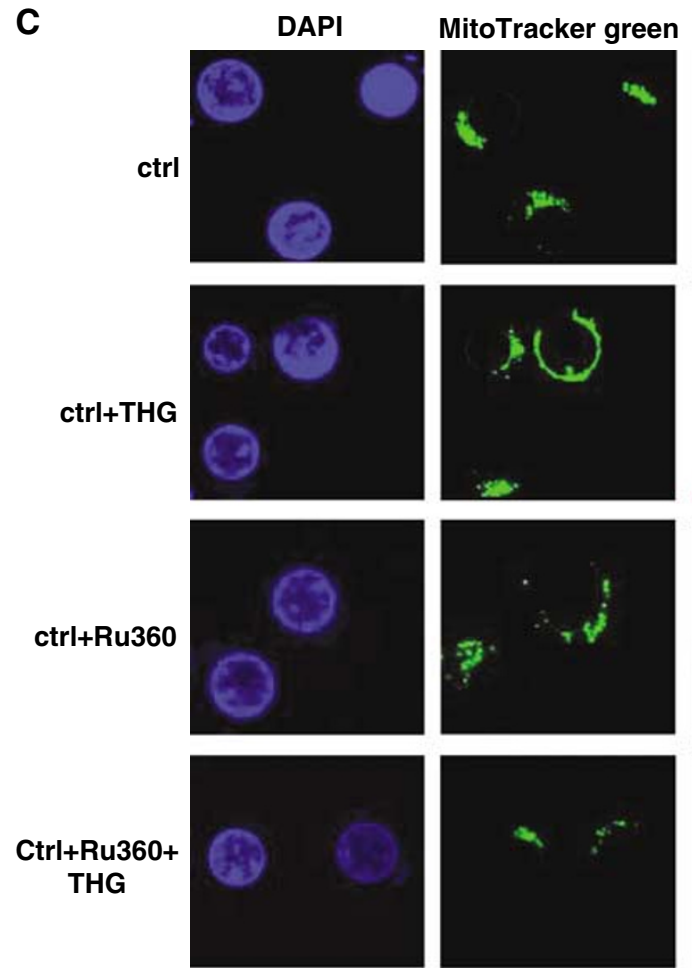
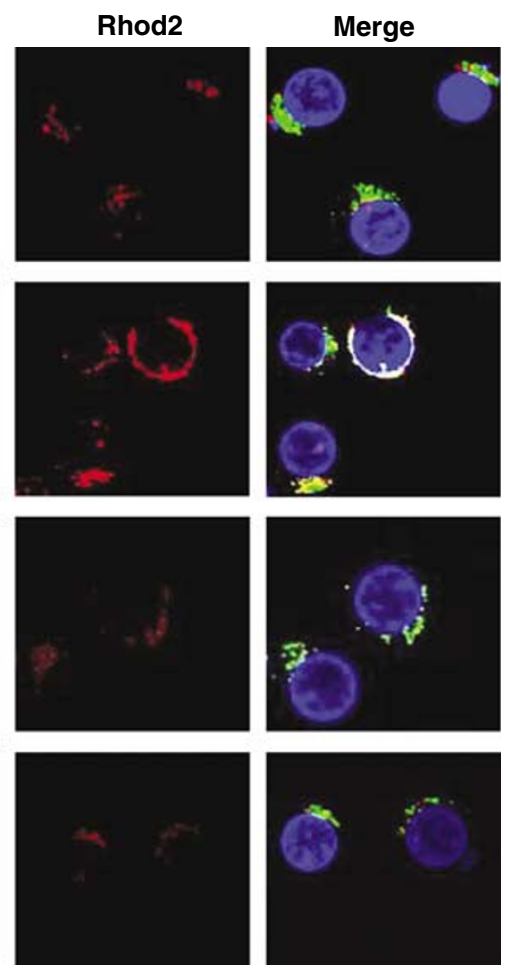

Figure 1 (Continued)

THG + CsA. Figure shows a representative example of three independent experiments. In each analysis, 10000 events were recorded. Figure 1B, left caption (d) shows a bar graph of cytosolic calcium levels expressed as mean Fluo3 fluorescence intensity normalized to control. The data are expressed as means \pm S.E. $(n=3)$. Results show that THG significantly increased Fluo3 fluorescence in CEM cells, which was not altered by either treatment with Ru360 (to block mitochondrial calcium uptake), by MPT inhibition with CsA or by siRNA Cyp-D knockdown. Figure 1B, right captions show FACS analysis histograms of Rhod2-AMstained CEM cells as described above for Fluo3-AM. Figure 1B, right caption (d) shows a bar graph of mitochondrial calcium levels expressed as mean Rhod2 fluorescence intensity normalized to control as described above for Fluo3. Results show that THG significantly increased Rhod2 fluorescence in CEM cells, which was effectively blocked by treatment with Ru360, but not by MPT inhibition with CsA or by siRNA Cyp-D knockdown. Figure $1 C$ shows representative confocal images of CEM cells loaded with 4'-6-diamidino-2-phenylindole (DAPI), MitoTracker green and Rhod2-AM and then treated with THG or THG +Ru360. Merge shows that THG increased Rhod2 fluorescence in mitochondria of CEM cells that was blocked by Ru360. Results support those obtained by FACS analysis.

THG causes loss of mitochondrial membrane potential $\left(\Delta_{\Psi \mathrm{m}}\right)$ : evidence of $\mathrm{Ca}^{2+}$-induced MPT. $\Delta_{\Psi \mathrm{m}}$ was determined by monitoring the fluorescence of the cationic potentiometric dye TMRM performed as described in the
Materials and Methods section. Figure 2 shows representative two-dimensional colour density plots of TMRM-stained cells showing percentage numbers of cells with intact $\Delta_{\Psi m}$ (TMRM fluorescence in top right quadrant) versus percentage number of cells with reduced $\Delta_{\Psi \mathrm{m}}$ (TMRM fluorescence in bottom left quadrant). Figure shows TMRM fluorescence of cells treated for $36 \mathrm{~h}$ with (a) RPMI (control), (b) THG, (c) THG + Ru360, (d) THG + siRNA Cyp-D and (e) $T H G+C s A$. The figure shows a representative example of three independent experiments. In each analysis, 10000 events were recorded. Percentage cells with TMRM fluorescence at $36 \mathrm{~h}$ : (a) control $\sim 93 \%$, (b) THG $\sim 8 \%$, (c) THG + Ru360 $\sim 53 \%$, (d) THG after siRNA Cyp-D knockdown $\sim 59 \%$ and (e) $\mathrm{THG}+\mathrm{CsA} \sim 68 \%$. Figure $2 \mathrm{f}$ shows the percentage (mean \pm S.E.) of CEM cells with intact $\Delta_{\Psi \mathrm{m}}$ at $0,12,24$ and $36 \mathrm{~h}$ after treatment with THG as described above and shows that THG induced a timedependent loss of TMRM fluorescence over $36 \mathrm{~h}$ which was significantly blocked by Ru360, CsA and by siRNA Cyp-D knockdown.

THG induces mitochondrial cytochrome $c$ release, caspase-3 cleavage and DNA fragmentation of CEM cells. Figure $3 A$ shows representative results of cytochrome $c$ immunoblots after cells were co-incubated with THG + Ru360 (top panel), THG + siRNA Cyp-D (middle panel) or THG + CsA (bottom panel). $\beta$-Actin was used as a loading control. Results show that THG induced a timedependent increase in cytosolic cytochrome $c$ band, which was significantly reduced by each of the treatments 

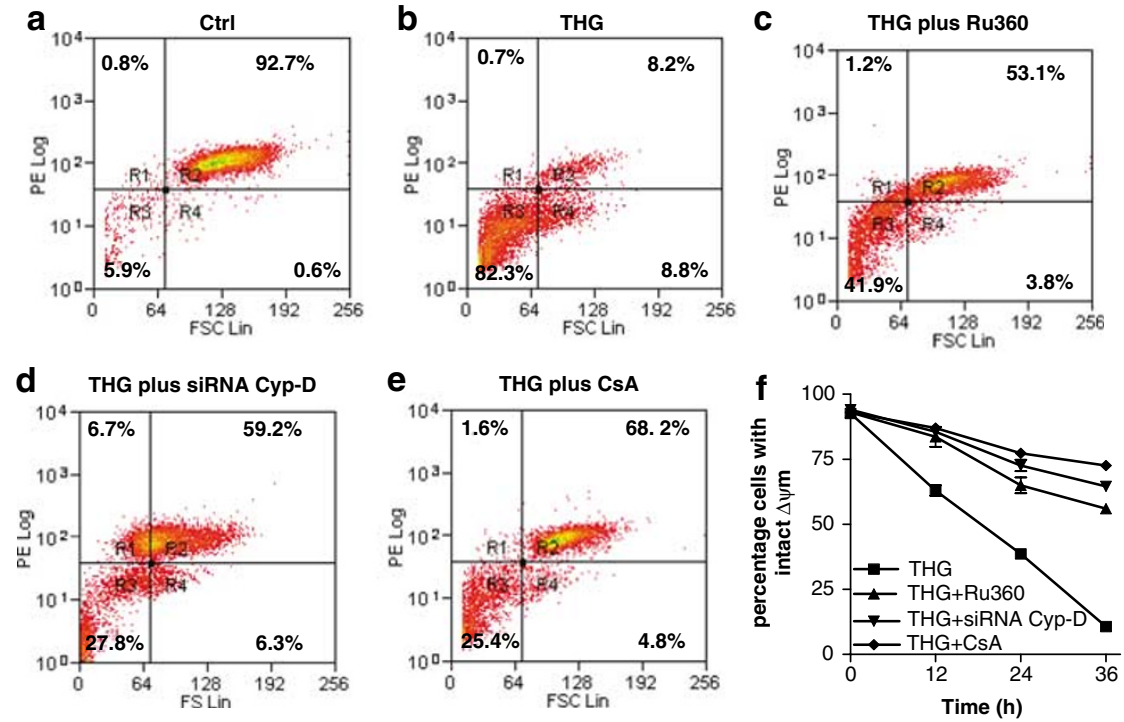

Figure 2 Representative TMRM fluorescence two-dimensional colour density plots showing percentage number of cells with intact $\Delta_{\Psi \mathrm{m}}$ (TMRM fluorescence in top right quadrant) and percentage number of cells with reduced $\Delta_{\Psi m}$ (TMRM fluorescence in bottom left quadrant) $36 \mathrm{~h}$ after treatment with THG. (a) RPMI (control), (b) THG, (c) $T H G+R u 360$, (d) THG + siRNA CyD and (e) THG + CsA. The cells were loaded with $250 \mathrm{nM}$ TMRM for $15 \mathrm{~min}$ and the red fluorescence was immediately measured by flow cytometry using the PE setting as described under 'Materials and Methods'. In each analysis, 10000 events were recorded. Panel (f) shows a graph of the percentage (mean \pm S.E.) of CEM cells with intact $\Delta_{\Psi \mathrm{m}}$ determined at $0,12,24$ and $36 \mathrm{~h}$ after treatment with THG as described above

described above. Figure 3B shows a bar graph of mean caspase-3 activity $36 \mathrm{~h}$ after cells were treated with $\mathrm{THG} \pm$ Ru360, Cyp-D siRNA or CsA. Results show that each treatment significantly inhibited caspase-3 processing. Figure $3 \mathrm{C}$ shows representative cell cycle analysis FACS histograms of propidium iodide (PI)-stained CEM cells after treatment with (a) RPMI (control), (b) THG, (c) $T H G+R u 360$, (d) THG + siRNA Cyp-D and (e) THG + CsA for $36 \mathrm{~h}$. Inset figures show results of DAPI staining of cells shown in corresponding FACS histograms. Results show that inhibition of mitochondrial $\mathrm{Ca}^{2+}$ increase or MPT activation blocked induction of apoptosis.

CsA blocks THG-induced cell death in siRNA Cyp-D knockdown cells. To investigate whether CsA was nonspecifically (not by its effects on the MPT) blocking THG-induced cell death, we treated siRNA Cyp-D knockdown cells for $48 \mathrm{~h}$ with THG in the presence and absence of CsA. Figure 4A shows that CsA blocked THGinduced loss of cell viability in siRNA Cyp-D knockdown cells. These results indicated that THG-mediated release of cytochrome $c$ from the mitochondria of CEM cells involved the MPT as well as a non-MPT pathway. Figure 4B shows electron micrographs (EM) of the mitochondrial ultrastructure of CEM cells after treatment with (a) RPMI control, (b) THG and (c) $T H G+C s A$ for $36 \mathrm{~h}$. Results show that CsA preserved the ultrastructure of the mitochondrial cristae (indicated by arrow heads).

Bax translocation and $\mathrm{N}$-terminal exposure is independent of MPT. As Bax is known to regulate cytochrome $c$ release and cell death, we next investigated the role of Bax in THG-induced cell death. Figure 5A shows representative Bax (N20 antibody) immunoblots performed on the mitochondrial fractions taken from CEM cells treated with (top panel) $T H G \pm$ Ru360, (middle panel) $T H G \pm$ siRNA Cyp-D and (bottom panel) $T H G \pm C s A$ for $24 \mathrm{~h}$. Manganese superoxide dismutase (MnSOD) was used as a loading control. Results show that THG caused a time-dependent increase in mitochondrial Bax which, was not significantly altered by each of the treatments described above, indicating that Bax activation and translocation to mitochondria was independent of the MPT. We next treated CEM cells with THG \pm the $\mathrm{Ca}^{2+}$ chelating agent BAPTA-AM to determine the role of cytosolic $\mathrm{Ca}^{2+}$ in Bax activation. Figure 5B (part a) shows representative Fluo3-AM FACS analysis histograms as described in Figure 1. Thin black trace control; heavy black trace $\sim$ THG and heavy green trace THG + BAPTA-AM. Figure 5B, (part b) shows bar graph of cytosolic calcium levels \pm BAPTA-AM expressed as mean Fluo3 fluorescence intensity normalized to control as described in Figure 1. The results show that BAPTA-AM blocked cytosolic $\mathrm{Ca}^{2+}$ increase. Figure 5B (part c) shows Bax immunoblot after treatment of cells with THG \pm BAPTAAM for $24 \mathrm{~h}$ as described in Figure 5A showing that Bax activation and translocation to mitochondria was not significantly altered by BAPTA-AM. These results indicated that Bax activation was independent of THG-induced cytosolic $\mathrm{Ca}^{2+}$ increase and MPT.

siRNA Bax knockdown blocks THG-induced release of cytochrome $c$ and leads to caspase-independent cell death. Figure $6 \mathrm{~A}$ shows results of an immunoblot for Bax protein expression after transfection with control siRNA (left) and Bax siRNA (right). Right lane shows $\sim 90 \%$ decrease in Bax protein after transfection with Cyp-D siRNA compared to control. Figure 6B shows (a) representative FACS analysis histograms of Fluo3-AM-stained CEM cells \pm THG before 
A

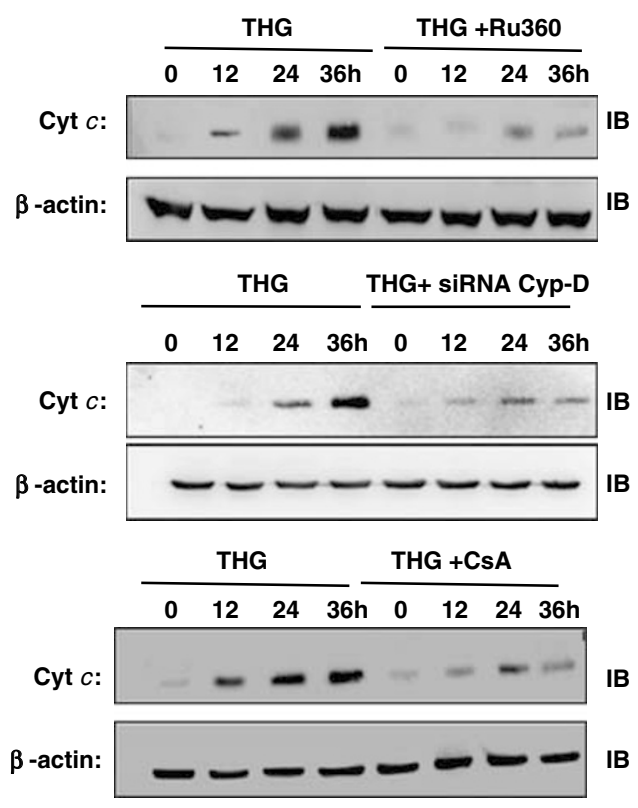

B

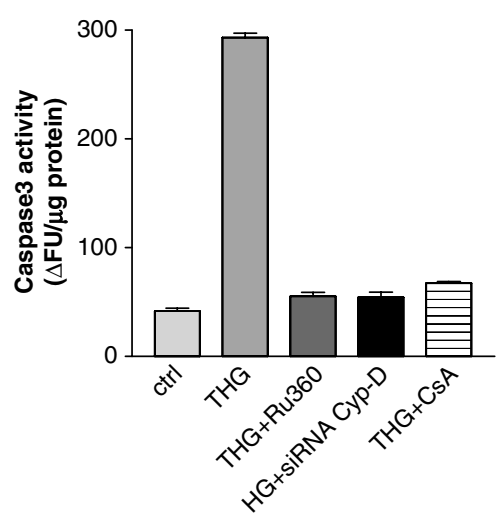

C

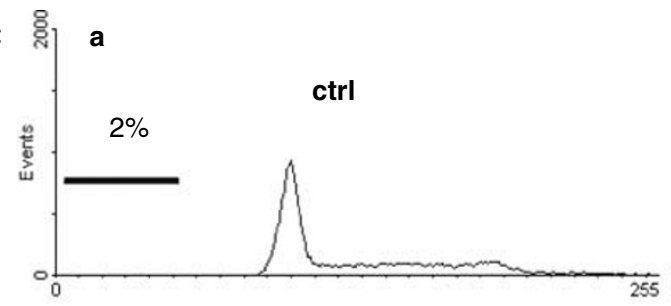

DNA content by PI fluorescence
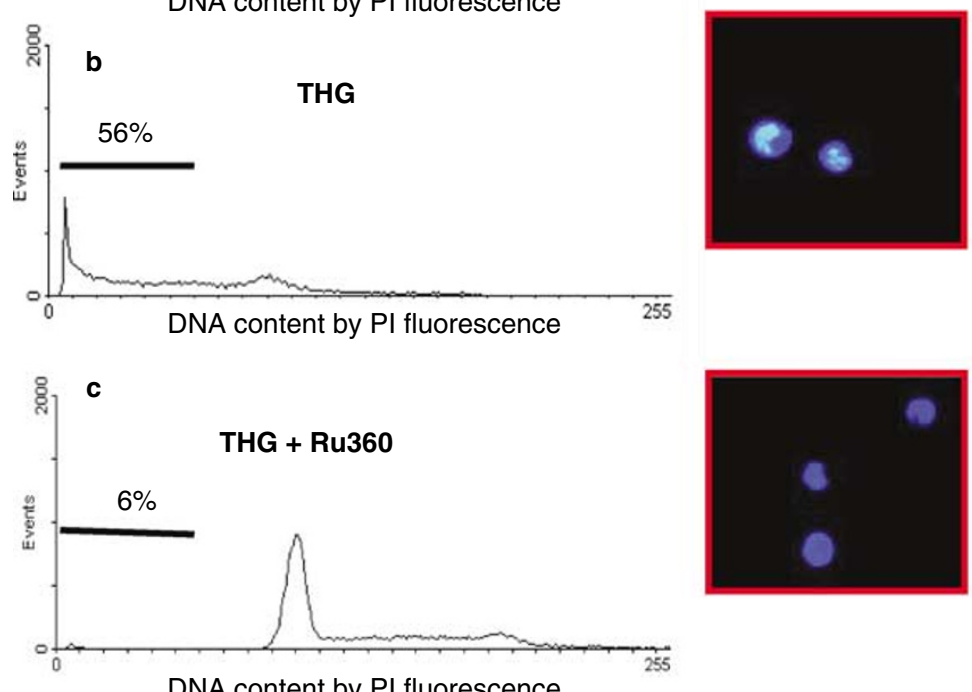

DNA content by PI fluorescence
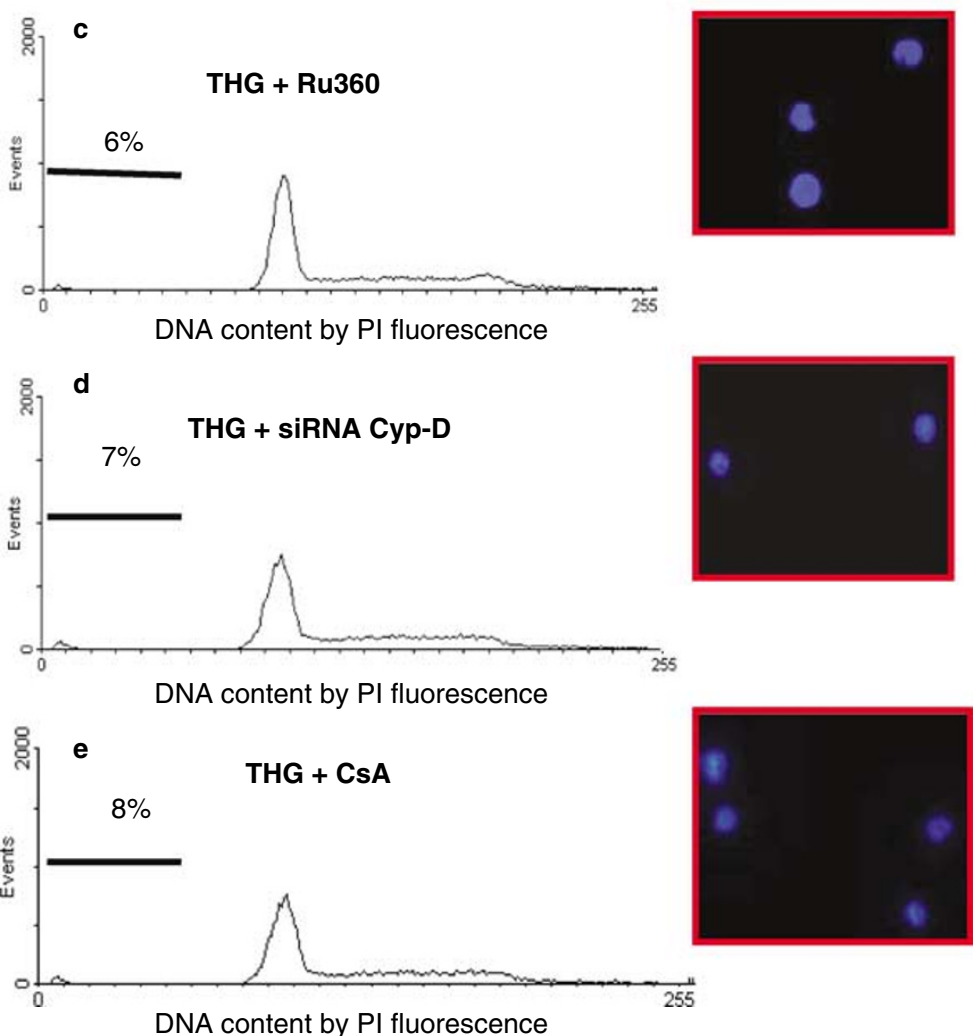

Figure 3 (A) Top panel shows representative cytochrome $c$ immunoblot determined on the cytosolic fractions of CEM cells before and after treatment with $\mathrm{THG} \pm \mathrm{Ru} 360$ for $0,12,24$ and $36 \mathrm{~h}$. $\beta$-Actin was used as a loading control. Middle panel shows representative cytochrome $c$ immunoblot determined on the cytosolic fractions of CEM cells after treatment with THG for $0,12,24$ and $36 \mathrm{~h}$ before and after Cyp-D siRNA knockdown. $\beta$-Actin was used as a loading control. Bottom panel shows representative cytochrome $c$ immunoblot determined on the cytosolic fractions of CEM cells before and after treatment with THG \pm CsA for $0,12,24$ and $36 \mathrm{~h}$. $\beta$-Actin was used as a loading control. (B) Figure shows bar graph of caspase-3 activity (mean \pm S.E.) before and after treatment with THG \pm Ru360; THG \pm CsA or THG before and after treatment with Cyp-D siRNA for $36 \mathrm{~h}$ determined as described under 'Methods and Materials'. (C) Representative cell cycle analysis FACS histograms of PI-stained CEM cells after treatment with (a) RPMI (control), (b) THG, (c) THG + Ru360, (d) THG after pretreatment with Cyp-D siRNA and (e) THG + CsA for $36 \mathrm{~h}$. Percentage cells containing hypodiploid amount of DNA (sub-G1 fraction) indicated. Inset figures show results of DAPI staining of cells shown in corresponding FACS histograms

and after siRNA Bax knockdown: black trace: parental control; green trace: siRNA Bax. (b) Bar graph of cytosolic calcium levels (mean \pm S.E) expressed as mean Fluo3 fluorescence intensity normalized to control. (c) Representative FACS analysis histograms of Rhod2-AMstained CEM cells \pm THG before and after siRNA Bax knockdown: black traces parental cells: control, THG and THG + Ru360; green traces siRNA Bax knockdown cells: control, THG and THG + Ru360. (d) Bar graph of mitochondrial calcium levels (mean \pm S.E) expressed as mean Rhod2 fluorescence intensity normalized to control. Figure $6 \mathrm{C}$ shows a representative cytochrome $c$ immunoblot 

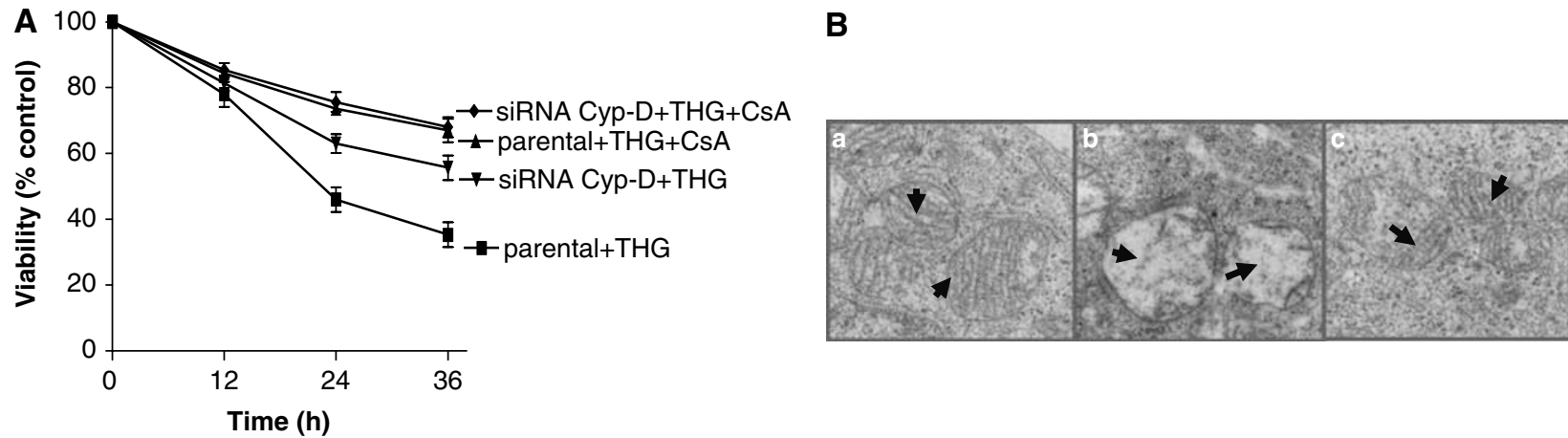

Figure 4 (A) Parental CEM cells and Cyp-D knockdown cells were treated with THG \pm CsA and cell viability was determined by trypan blue exclusion at $0,12,24$ and $36 \mathrm{~h}$. (B) Mitochondrial ultrastructure of CEM cell mitochondria determined by TEM before and after treatment with THG \pm CsA for $36 \mathrm{~h}$. (a) RPMI control, (b) THG and (c) THG + CsA (arrowheads point to mitochondrial internal cristae structure)

A

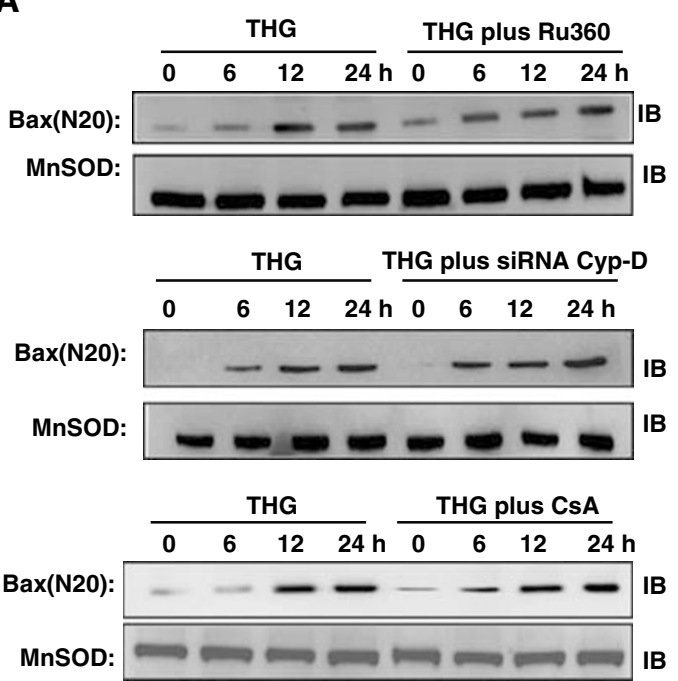

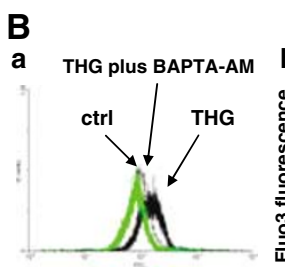

Cytosolic calcium

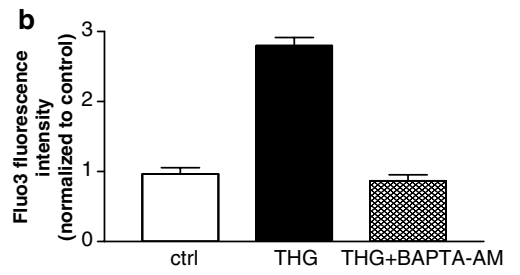

THG THG plus BAPTA-AM

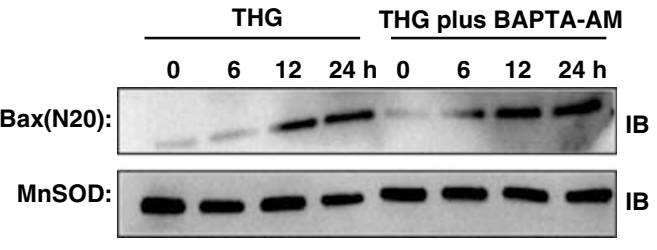

Figure 5 (A) Top panel shows representative Bax (N20 antibody) immunoblot determined on the mitochondrial fractions of CEM cells before and after treatment with $\mathrm{THG} \pm$ Ru360 for $0,6,12$ and $24 \mathrm{~h}$. MnSOD was used as a loading control. Middle panel shows representative Bax (N20 antibody) immunoblot determined on the mitochondrial fractions of CEM cells treated with THG for $0,6,12$ and $24 \mathrm{~h}$ before and after pretreatment with Cyp-D siRNA. MnSOD was used as a loading control. Bottom panel shows representative Bax (N20 antibody) immunoblot determined on the mitochondrial fractions of CEM cells before and after treatment with THG \pm CsA for $0,6,12$ and $24 \mathrm{~h}$. MnSOD was used as a loading control. (B): (a) Representative FACS analysis histograms of Fluo3-AM-stained CEM cells after treatment with THG $\pm B A P T A-A M$ (determined as described in Figure 1B). Thin black trace shows control cells; heavy black trace shows cells after treatment with THG and heavy green trace shows cells after treatment with THG + BAPTA-AM. (b) Bar graph showing cytosolic calcium levels in the presence and absence of BAPTA-AM expressed as mean Fluo3 fluorescence intensity normalized to control. The data are expressed as means \pm S.E. $(n=3)$. (c) Shows representative Bax (N20 antibody) immunoblot determined on the mitochondrial fractions of CEM cells before and after treatment with BAPTA-AM for $0,6,12$ and $24 \mathrm{~h}$. MnSOD was used as a loading control

Figure 6 (A) results of an immunoblot of Bax (N-20 antibody) protein expression performed on CEM cells after transfection with either control siRNA or Bax siRNA. (B): (a) Representative FACS analysis histogram of Fluo3-AM-stained CEM cells before and after siRNA Bax knockdown in the presence and absence of THG. Black trace: parental control cells \pm THG; green trace: siRNA Bax \pm THG. (b) Bar graph of cytosolic calcium levels in CEM cells after treatment with THG before and after siRNA Bax knockdown (mean \pm S.E.) expressed as mean Fluo3 fluorescence intensity normalized to control. (c) Representative FACS analysis histograms of Rhod2-AM-stained CEM cells before and after siRNA Bax knockdown in the presence and absence of THG \pm Ru360. Black trace: parental control cells, parental control cells + THG and parental control cells + THG + Ru360; green trace: siRNA Bax control, siRNA Bax + THG and siRNA Bax + THG + Ru360. (d) Bar graph of mitochondrial calcium levels in CEM cells before and after siRNA Bax knockdown in the presence and absence of THG or THG + Ru360 (mean \pm S.E) expressed as mean Rhod2 fluorescence intensity normalized to control. (C) Representative cytochrome $c$ immunoblot determined on the cytosolic fractions of CEM cells treated with THG for 0, 12, 24 and $36 \mathrm{~h}$ before and after siRNA Bax knockdown. $\beta$-Actin was used as a loading control. (D) Representative TMRM fluorescence two-dimensional colour density plots showing percentage number of cells with intact $\Delta_{\Psi m}$ and percentage number of cells with reduced $\Delta_{\Psi m}$ before and after treatment with THG for $48 \mathrm{~h}$ (as described in Figure 2). (a) Parental CEM cells + THG, (b) Parental CEM cells + THG + zVADfmk, (c) siRNA Bax knockdown CEM cells + THG, (d) siRNA Bax knockdown CEM cells + THG + zVADfmk, (e) siRNA Bax knockdown CEM cells + THG + CsA. The cells were loaded with $250 \mathrm{nM}$ TMRM for $15 \mathrm{~min}$ and the red fluorescence was immediately measured by flow cytometry using the PE setting as described under 'Materials and Methods' In each analysis, 10000 events were recorded. Inset figure (f) shows a graph of the percentage (mean \pm S.E.) of CEM parental and siRNA Bax knockdown cells with intact $\Delta_{\Psi m}$ determined at 0,24 and $48 \mathrm{~h}$ after treatment with THG as described above. (E) Graph showing viability of CEM parental and siRNA Bax knockdown cells after treatment with THG \pm zVADfmk and siRNA Bax knockdown cells + CsA for 0, 24, 48, 72 and $96 \mathrm{~h}$ assayed by trypan blue exclusion. (F) Representative FACS analysis cell cycle histograms of PI-stained CEM parental and siRNA Bax knockdown CEM cells after treatment with THG for $0,24,48,72$ and $96 \mathrm{~h}$. Percentage cells containing hypodiploid amount of DNA (sub-G1 fraction) indicated. (G) Bar graph of caspase-3 activity after treatment of CEM parental and siRNA Bax knockdown CEM cells with THG for $0,12,24,36$ and $48 \mathrm{~h}$ 
determined on cytosolic fractions taken from CEM parental cells and CEM siRNA Bax knockdown cells after treatment with THG every $12 \mathrm{~h}$ for a total of $36 \mathrm{~h}$. Results show that cytosolic cytochrome $c$ protein band was blocked by siRNA Bax knockdown. Figure $6 \mathrm{D}, \Delta_{\Psi \mathrm{m}}$ was determined in parental cells treated with $T H G \pm z V A D f m k$ and siRNA Bax knockdown cells treated with $\mathrm{THG} \pm \mathrm{zVADfmk}$ or CsA by monitoring TMRM fluorescence as described for Figure 2. Figure shows TMRM fluorescence of cells monitored at 0 , 24 and $48 \mathrm{~h}$ treated with (a) THG, (b) THG + zVADfmk, (c) THG + siRNA Bax, (d) THG + siRNA Bax + zVADfmk and (e) $\mathrm{THG}+$ siRNA Bax $+\mathrm{CsA}$. After $48 \mathrm{~h}$ treatment of CEM

A

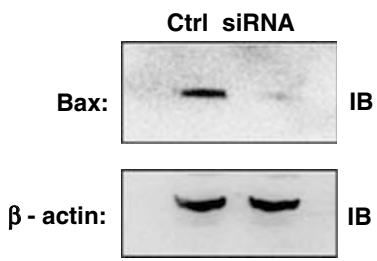

B

a $\quad \begin{gathered}\text { Cytosolic calcium } \\ \text { (Fluo3 fluorescence) }\end{gathered}$

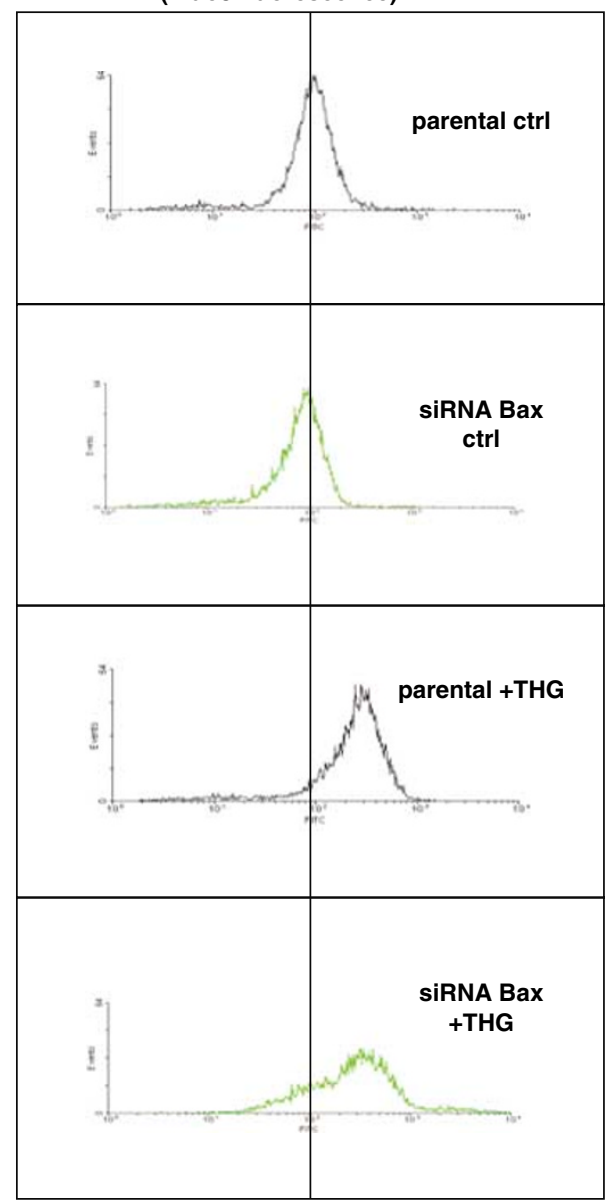

b

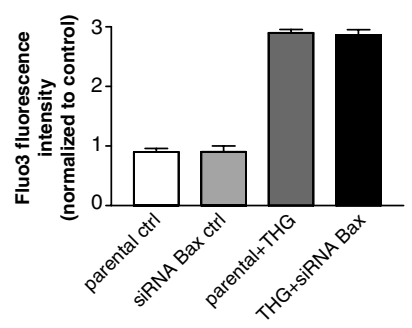

c Mitochondrial calcium C (Rhod2 fluorescence)
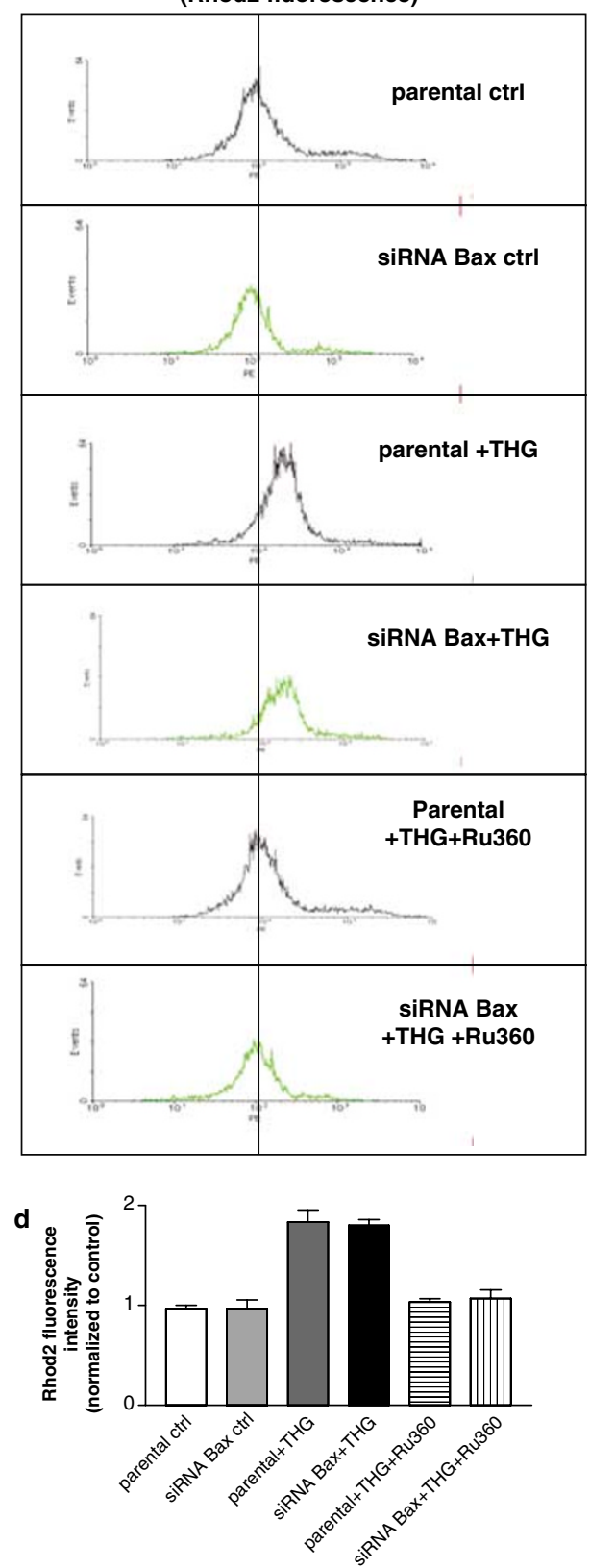
C
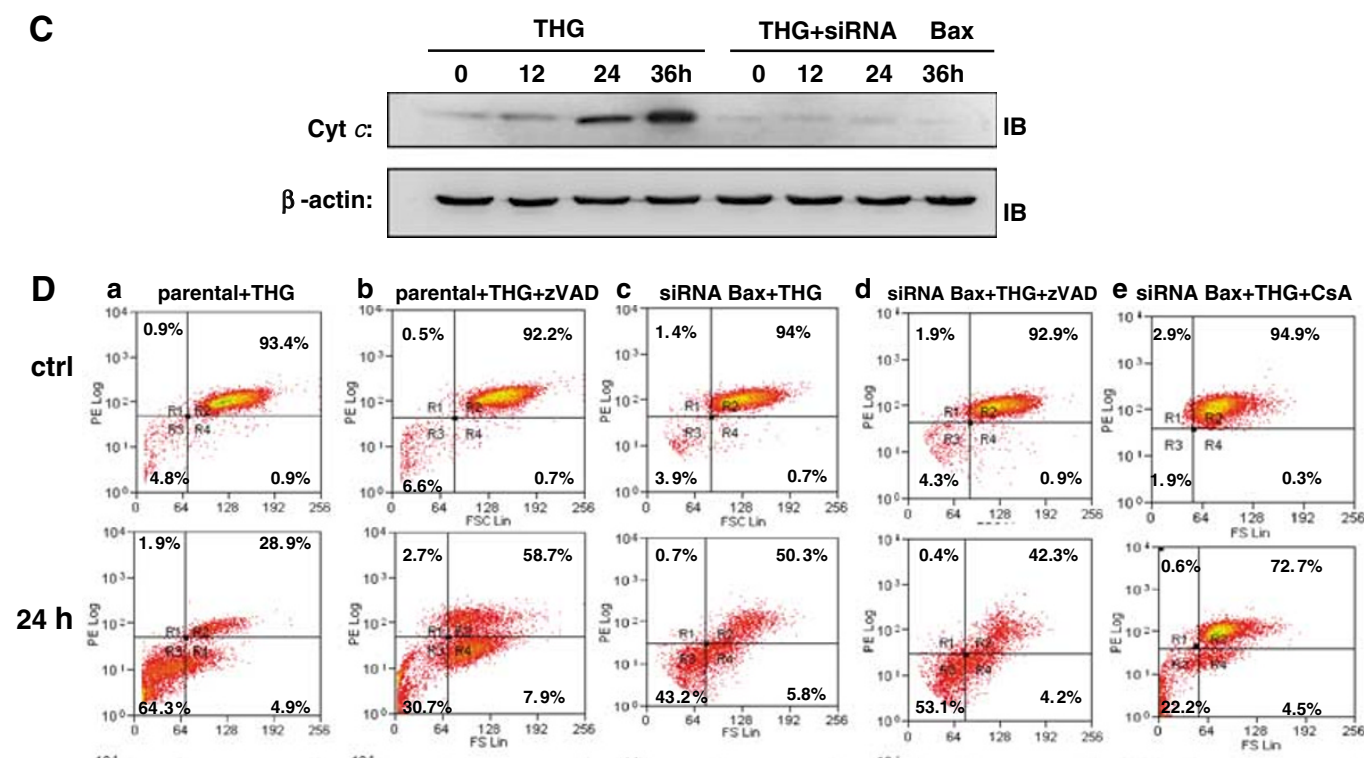

$48 \mathrm{~h}$
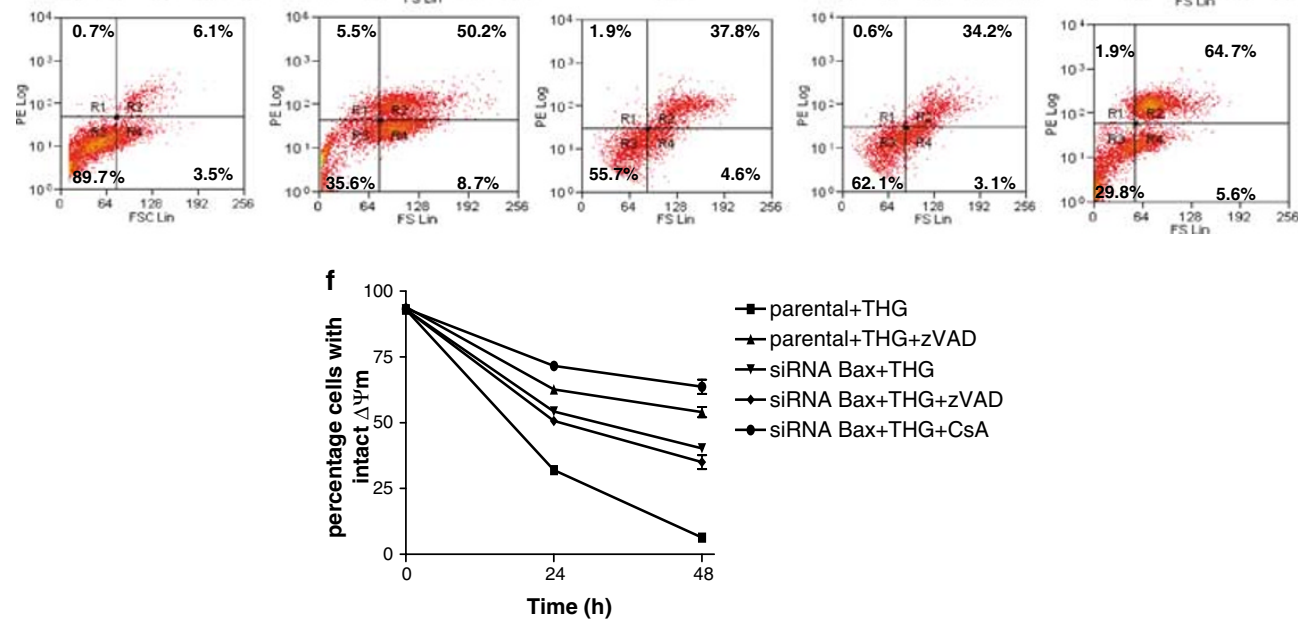

Figure 6 (Continued)

parental cells with THG, loss of TMRM fluorescence (lower left quadrant of colour density plot) occurred in panel a $90 \%$ of cell population compared to $36 \%$ in cells treated with THG + zVADfmk, panel $b$. After $48 \mathrm{~h}$ treatment of siRNA Bax knockdown cells with THG, loss of TMRM fluorescence occurred, in panel $c \sim 56 \%$ of cell population compared to $62 \%$ in cells treated with zVADfmk as showed in panel d, whereas treatment with CsA caused loss of TMRM fluorescence in $\sim 30 \%$ of cell population, panel e. Results show that THG-induced loss of $\Delta_{\Psi m}$ in parental cells was blocked by caspase inhibition, whereas loss of $\Delta_{\Psi \mathrm{m}}$ in siRNA Bax knockdown cells was not blocked by caspase inhibition, but was significantly protected by CsA. Figure 6D, (f) shows the percentage (mean \pm S.E.) of CEM cells with intact $\Delta_{\Psi \mathrm{m}}$. Figure $6 \mathrm{E}$ shows viability of THG-treated parental cells and siRNA Bax knockdown cells in the presence and absence of zVADfmk. Results show that zVADfmk blocked loss of cell viability induced by THG in parental cells, but not in siRNA Bax knockdown cells. Figure 6F shows representative FACS analysis cell cycle histograms of PI-stained, THG-treated CEM parental cells and siRNA Bax knockdown cells monitored at $0,24,48,72$ and $96 \mathrm{~h}$. Results show that THG treatment induced a significant increase in the subG1 fraction of parental CEM cells but not in siRNA Bax knockdown CEM cells. Figure $6 \mathrm{G}$ shows a bar graph of caspase-3 activity at $0,12,24,36$ and $48 \mathrm{~h}$ determined as described for Figure $3 \mathrm{~B}$. Results show that siRNA Bax knockdown inhibited THG-mediated caspase-3 processing. Together, these results indicated that in the absence of Bax, THG-induced cell death is caspase independent.

Contribution of the MPT to the release of cytochrome $c$ from mitochondria. During ER-stress-induced apoptosis, we observed that Bax was necessary but not sufficient for complete cytochrome $c$ release from mitochondria. We, therefore, considered that the MPT was involved in the mobilization of cytochrome $c$ from mitochondria and Bax provided a cytochrome $c$ access channel to the cytosol. To investigate the role of the MPT in the release of cytochrome $c$ release, we treated isolated rat liver mitochondria (RLM) with either $\mathrm{Ca}^{2+}$ to induce the MPT or $\mathrm{Ca}^{2+}+\mathrm{CsA}$ to block the MPT and determined the relative amount of cytochrome $c$ 
E

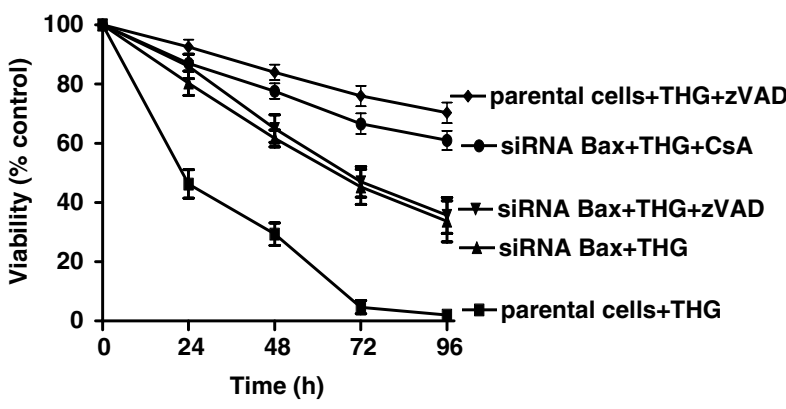

$\mathbf{F}$

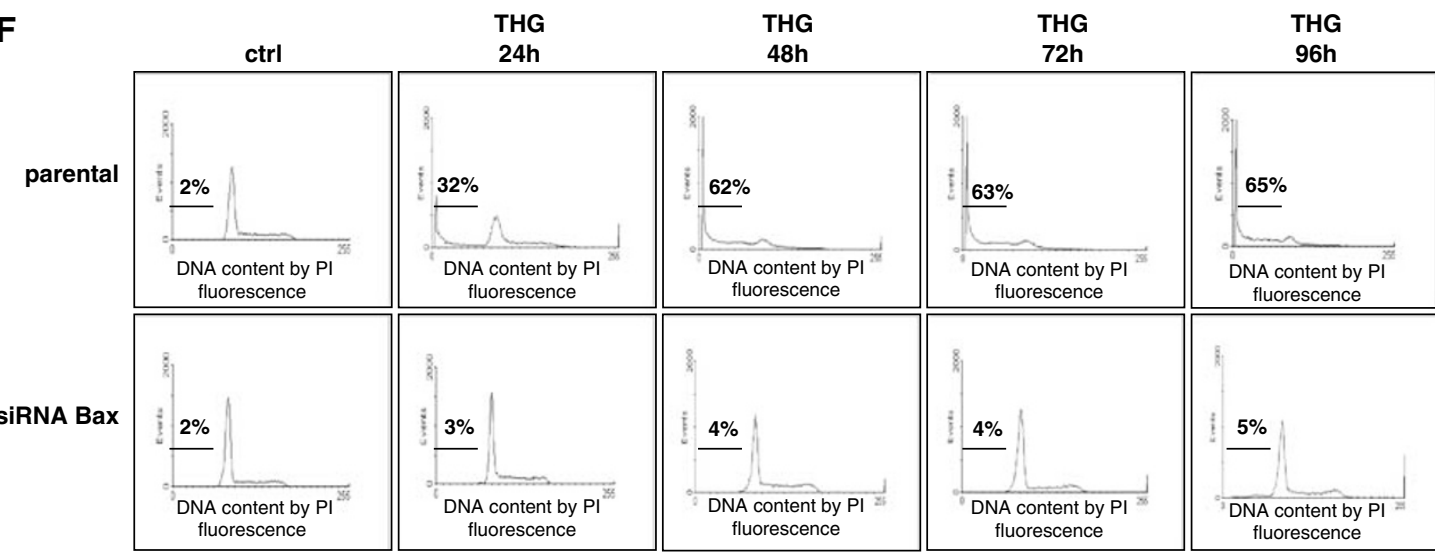

G

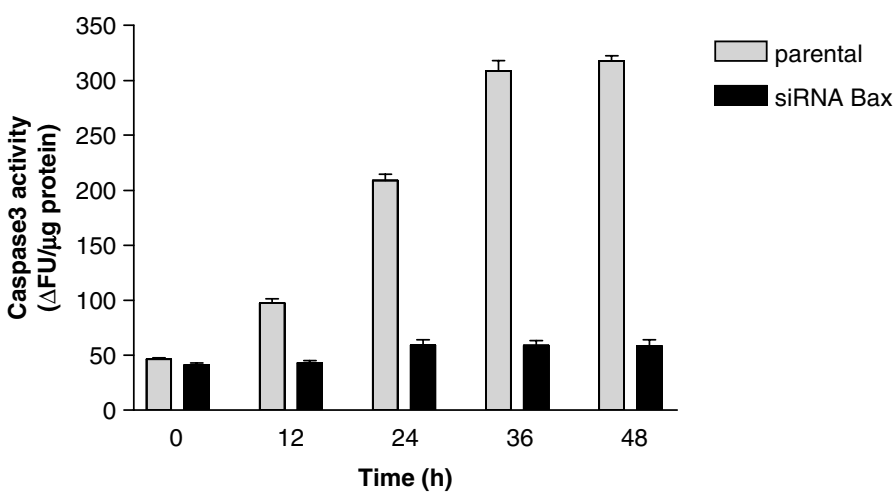

Figure 6 (Continued)

released into the mitochondrial suspension buffer by Western blot. To investigate the role of Bax as a poreforming protein in the mitochondrial outer membrane, we determined the proportion of cytochrome $c$ in the mitochondrial inter-membrane space by removing the mitochondrial outer membrane of RLM with digitonin (DIG) and determining cytochrome $c$ release into the mitochondrial suspension buffer by Western blot. Figure 7A shows a representative example of $\mathrm{Ca}^{2+}$-induced swelling profile of RLM in the presence and absence of CsA showing that CsA blocks large amplitude swelling indicative of the MPT. Figure 7B top panel shows oxygen consumption and calculated respiratory control ratios (RCR) of $R L M$ suspensions (a) before and (b) after treatment with DIG; middle panel shows representative results of an immunoblot for cytochrome $c$ performed on aliquots of mitochondrial suspension buffer (a) after treatment with $\mathrm{Ca}^{2+} \pm \mathrm{CsA}$ and (b) after treatment with either $\mathrm{Ca}^{2+}$ or DIG (see Materials and Methods); bottom panel shows bar graph of relative cytochrome $c$ band density determined from the immunoblots shown in 'middle panel' measured by scanning densitometry. Results show that the major fraction of cytochrome $c$ is released upon MPT activation and a minor fraction is released by removing the mitochondrial outer membrane. In conjunction with our in situ data, these results suggest that the Bax-mediated permeabilization of the outer mitochondrial membrane provides the critical access point for cytochrome $c$ release to the cytosol during ER-stress-induced apoptosis, but requires the MPT- and non-MPT-mediated structural changes to cristae for complete release of cytochrome $c$ and activation of apoptosis. However, this is not to say that ER-stress-induced activation of Bax only causes outer 
A

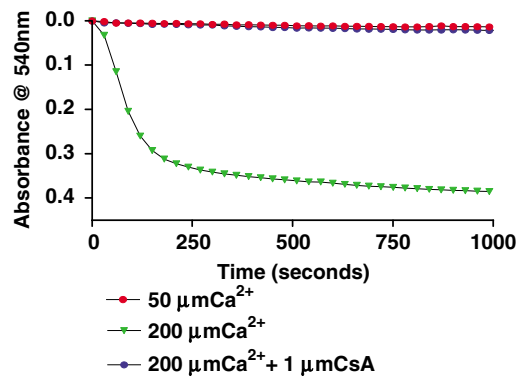

B

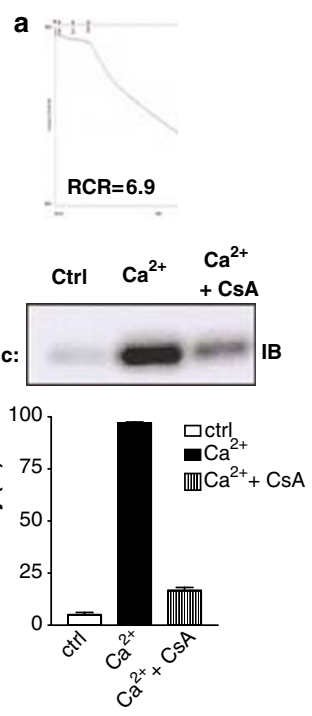

b

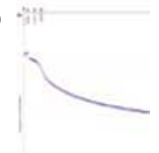

$\mathrm{RCR}=3.7$
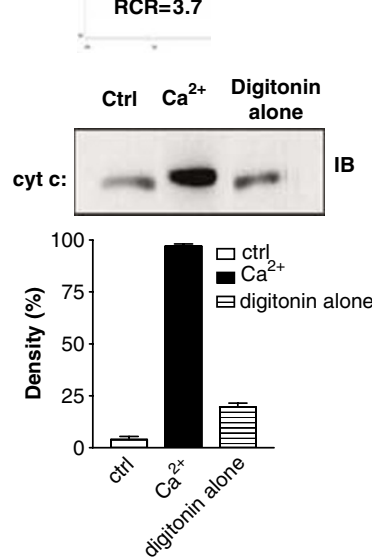

Figure 7 (A) The figure shows representative example of $\mathrm{Ca}^{2+}$-induced swelling profile of RLM in the presence and absence of CsA. RLM (0.5 mg protein $\left./ \mathrm{ml}\right)$ were treated with $200 \mu \mathrm{M} \mathrm{Ca}^{2+} \pm \mathrm{CsA}$ and absorbance at $540 \mathrm{~nm}$ was monitored as described under 'Materials and Methods'. (B) Top panel: (a) Oxygen consumption of isolated RLM with estimated RCR 6.9, (b) oxygen consumption of RLM after treatment with DIG with estimated RCR $\sim 3.7$. Middle panel: (a) representative cytochrome $c$ immunoblot determined on the supernatant fractions taken from RLM suspensions treated with $\mathrm{Ca}^{2+} \pm \mathrm{CsA}$. (b) Representative cytochrome $c$ immunoblot determined on the supernatant fractions taken from RLM suspensions treated with $\mathrm{Ca}^{2+}$ or DIG. Bottom panel shows bar graph of cytochrome $c$ band density determined from the immunoblots shown in 'middle panel' measured by scanning densitometry

membrane permeabilization, as it may also be involved in facilitating mitochondrial inner membrane changes which have not been investigated here.

\section{Discussion}

In this study, we investigated mitochondrial events regulating ER-stress-induced apoptosis in human leukemic CEM cells using the drug THG. Three independent lines of evidence showed a key role for increased mitochondrial $\mathrm{Ca}^{2+}$ in THGmediated cytochrome $c$ release and induction of apoptosis: (1) pharmacological inhibition of mitochondrial $\mathrm{Ca}^{2+}$ increase (using Ru360 to block uniporter function), (2) CsA, the classical MPT inhibitor and (3) siRNA knockdown of Cyp-D all blocked cytochrome $c$ release and induction of apoptosis. These results indicated that increased mitochondrial $\mathrm{Ca}^{2+}$ levels and MPT activation were required for the induction of CEM cell death. However, as CsA is relatively nonspecific in its action, we also considered that, in addition to its effects on the MPT, CsA might be inhibiting apoptosis via an additional mechanism. ${ }^{22-26}$ To determine the role of CsA in the regulation of THG-induced apoptosis, we treated siRNA Cyp-D knockdown CEM cells with THG in the presence and absence of CsA (Figure 4). We found that CsA protected CEM cells from THG-induced loss of viability even in the absence of Cyp-D, which indicated that in addition to its known effects on the MPT, CsA was protecting CEM cells against ER-stressinduced apoptosis by an additional mechanism. Although, the nature of this protective mechanism is unclear, EM results showed that CsA preserved the mitochondrial cristae structure. In agreement with this idea, previous findings of Scorrano et al. ${ }^{12}$ showed that mitochondrial cytochrome $c$ release, in this case induced by Bid, also involved a CsAsensitive structural remodelling of mitochondrial cristae.

THG-induced ER stress also caused the robust activation, translocation and N-terminal exposure of Bax in the mitochondria of CEM cells. The mechanism involved is currently unknown, but may involve the death receptor pathway via CHOP, DR5 and caspase-8 as previously reported, ${ }^{3}$ as we found that Bax translocation to mitochondria was not dependent on ER-stress-induced $\mathrm{Ca}^{2+}$ increase (Figure 5B, part c). The role of Bax in THG-induced apoptosis in CEM cells was investigated using siRNA to knockdown Bax protein expression. siRNA knockdown of Bax completely prevented THG-induced cytochrome $c$ release and partially inhibited apoptosis, indicating that Bax was required for the induction of cytochrome $c$-dependent apoptosis. However, Bax activation was unimpaired by either Ru360, CsA or Cyp-D knockdown, indicating that Bax alone was insufficient for successful induction of apoptosis during ER stress. This suggested that Bax and the MPT were independent signals that cooperated during ER-stress-induced apoptosis in CEM cells. Our results contrast a recent report which showed that the MPT signalled the activation and translocation of Bax to mitochondria during TMRM-induced photoexcitation. ${ }^{27}$ Although the reason for this discrepancy is not known, as the MPT can be either CsAregulated or CsA-unregulated, ${ }^{28-31}$ the photoexitation model might represent the unregulated MPT resulting from excessive free radical-induced redox stress which has previously been found to activate Bax. ${ }^{32-34}$

To investigate the relative contribution of Bax and the MPT to cytochrome $c$ release in CEM cells, we noted that after MPT inhibition a minor fraction of cytochrome $c$ (estimated at between 15 and 20\%) was detected by immunoblot. We 
considered that this minor fraction, which was insufficient to activate apoptosis, might represent the cytochrome $c$ residing in the mitochondrial inter-membrane space and not functioning in electron transport. To investigate this, we considered that we should be able to measure a similar quantity of cytochrome $c$ released from the inter-membrane space of isolated RLM after removing the mitochondrial outer membrane, and if this fraction of cytochrome $c$ was not involved in electron transport, then the mitochondria would remain coupled. Figure $6 \mathrm{~B}$ shows that after treatment with the detergent DIG to remove the outer mitochondrial membrane, RLM released approximately $\sim 15-20 \%$ of their total complement of cytochrome $c$ into the mitochondrial suspension buffer, but still remained significantly coupled (although RCR fell from 6.9 to 3.7). These studies provided evidence, although indirect, that during ER-stress-induced apoptosis, the MPT was responsible for the release of a major fraction of cytochrome $c$ derived from the mitochondrial ETC. As we also found that CsA blocked the release of approximately $80-85 \%$ of cytochrome $c$ from isolated RLM treated with $\mathrm{Ca}^{2+}$ to induce the MPT (Figure 7B (a) middle panel), this also supported the notion that the MPT was responsible for the release of the major fraction of cytochrome $c$ from RLM. These results support the idea that Bax forms a simple pore allowing cytochrome $c$ release into the cytosol as previously reported, ${ }^{35}$ and indicate that the MPT as well as structural changes occurring in the mitochondrial cristae are essential for the complete release of cytochrome $c$ during ER-stressinduced apoptosis (this idea is shown in Figure 8).

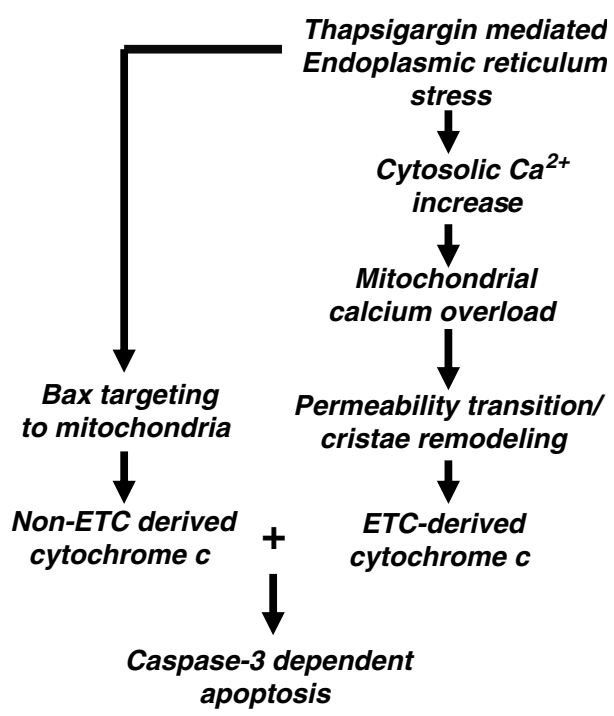

Figure 8 Hypothetical model showing key events regulating ER-stress-induced apoptosis in human leukemic CEM cells. The $\mathrm{Ca}^{2+}$-induced MPT and structura changes to the mitochondrial cristae and possibly contact junction (CJ) are responsible for the release of the major fraction of cytochrome $c$ from the ETC to activate apoptosis. Bax forms a simple pore or channel in the mitochondrial outer membrane to facilitate the release of cytochrome $c$ into the cytosol. In the model we show that Bax and the MPT are independent events activated by ER stress, but cooperate to bring about the complete release of cytochrome $c$ from mitochondria leading to caspase 3-dependent apoptosis
In conclusion, our results show that ER-stress-induced apoptosis requires cooperation between $\mathrm{Bax}$ and $\mathrm{Ca}^{2+}$ dependent mitochondrial changes including the MPT and CsA-sensitive structural changes to mitochondrial cristae. The result of this cooperation is a coordinated mechanism that regulates the complete release of mitochondrial cytochrome $c$ and activation of the mitochondrial death pathway.

\section{Materials and Methods}

Materials and cell culture. Chemicals including THG and BAPTA-AM were obtained from Molecular Probes (Eugene, OR, USA). Ru360 was purchased from Calbiochem (San Diego, CA, USA). Fluorescent probes including tetra-methyl rhodamine methyl ester (TMRM), Fluo3-AM, Rhod2-AM, MitoTracker green, PI and 4',6-diamidino-2-phenylindole, dihydrochloride (DAPI) were from Molecular Probes (Eugene, OR, USA). zVADfmk and DEVDfmk caspase inhibitors and CsA were purchased from Sigma Chemical Company.(St. Louis, MO, USA) CEM cells were passaged daily to maintain them in log-phase growth and kept at a nominal concentration of $2.5-5 \times 10^{5} / \mathrm{ml}$. Cell viability studies were performed by trypan blue exclusion method.

Apoptosis determination. THG was used at a concentration of $1 \mu \mathrm{M}$ unless otherwise stated. Cellular apoptosis was determined by performing FACS cell cycle analysis of PI $(20 \mu \mathrm{g} / \mathrm{ml})$-stained CEM cells. The percentage of cells in the sub-G1 zone was taken to indicate the percentage of cells undergoing apoptosis. DAPI $(3 \mu \mathrm{M})$ staining was also monitored by fluorescence microscopy to visually estimate cells containing fragmented DNA.

Caspase- 3 activity assays. EnzChek ${ }^{\circledR}$ Caspase- 3 Assay kits were purchased from Molecular probes (Eugene, OR, USA). CEM cell caspase-3 activity was determined using a caspase- 3 synthetic fluorescent substrate. Assays were performed according to the manufacturer's instructions. Substrate cleavage increases fluorescence, which was measured using Molecular Probes fluorometer model \# GEMINI XS (excitation at $342 \mathrm{~nm}$ and emission at $441 \mathrm{~nm}$ ).

FACS analysis for cytosolic and mitochondrial $\mathrm{Ca}^{2+}$ levels. Cytosolic $\mathrm{Ca}^{2+}$ levels were determined using the fluorescent dye Fluo3-AM (1 $\left.\mu \mathrm{M}\right)$ (log mode in FITC setting). Mitochondrial $\mathrm{Ca}^{2+}$ levels were determined using the fluorescent dye Rhod2-AM (250 nM) (log mode PE setting). Cells (parental, siRNA Cyp-D knockdown and siRNA Bax knockdown) were treated with $\mathrm{THG}+\mathrm{Ru} 360(10 \mu \mathrm{M})$ or CsA $(1 \mu \mathrm{M})$ for the times indicated and incubated with fluoresecent dyes for $15 \mathrm{~min}$ at $37^{\circ} \mathrm{C}$, and washed with PBS containing $10 \mathrm{mM}$ glucose and analysed immediately by flow cytometry. In each analysis, 10000 events were recorded.

Laser scanning confocal microscopy. CEM cells were loaded with $1 \mu \mathrm{M}$ Rhod2-AM in buffer containing $100 \mathrm{mM} \mathrm{KCl}, 10 \mathrm{mM}$ MOPS $\mathrm{pH}=7.2$ for $60 \mathrm{~min}$. After loading with Rhod2-AM, cells were transferred to primary culture for an additional $18 \mathrm{~h}$ to eliminate the residual cytosolic fraction of the Rhod2 probe. To determine the mitochondrial localization of the Rhod2 probe, cells were simultaneously loaded with $100 \mathrm{nM}$ MitoTracker green (a mitochondria-selective dye which is concentrated by active mitochondria) and $300 \mathrm{nM}$ DAPI in primary culture medium for $60 \mathrm{~min}$. Fluorescence Rhod2 images were acquired using $552 \mathrm{~nm}$ excitation and $581 \mathrm{~nm}$ emission; fluorescence images of MitoTracker green were acquired using $490 \mathrm{~nm}$ excitation and $516 \mathrm{~nm}$ emission and DAPI using $358 \mathrm{~nm}$ excitation and $461 \mathrm{~nm}$ emission as described previously. ${ }^{36}$

Determination of $\Delta_{\Psi \mathrm{m}}$. Determination of $\Delta_{\Psi \mathrm{m}}$ was performed as described previously. ${ }^{31}$ Briefly, cells were loaded with TMRM $(250 \mathrm{nM})$ for $15 \mathrm{~min}$ and red fluorescence was determined by FACS analysis using PE setting. In each analysis, 10000 events were recorded.

Transmission electron microscopy (TEM). CEM cells in the logarithmic proliferation phase were treated with THG $(1 \mu \mathrm{M}) \pm$ the inhibitors as described in figure legends. Cells were fixed with $2.5 \%$ glutaraldehyde in $0.1 \mathrm{M}$ cacodylate buffer,

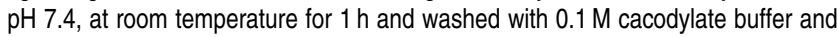
postfixed with $1 \%$ osmium tetraoxide in $0.1 \mathrm{M}$ cacodylate buffer and dehydrated with graded series of ethanol, and embedded in LX112. Thin sections were prepared, 
and stained with uranyl acetate. Specimens were examined on a JEOL $1000 \times$ electron microscope operating at $80 \mathrm{kV}$.

Subcellular fractionation. Subcellular fractionation was performed as described previously with the following modifications. ${ }^{37}$ Following treatment, cells $\left(\sim 1 \times 10^{7}\right)$ were harvested by centrifugation $\left(600 \times g\right.$ for $10 \mathrm{~min}$ at $\left.4^{\circ} \mathrm{C}\right)$. Cell pellets were washed with ice-cold PBS and suspended in HEPES buffer at $\mathrm{pH} 7.4$. Cells were disrupted using a $27 \frac{1}{2}$ gauge needle and the cell homogenate was centrifuged at $800 \times \mathrm{g}$ for $10 \mathrm{~min}$ at $4^{\circ} \mathrm{C}$ to remove nuclei and unbroken cells. The supernatant from this preparation was centrifuged at $10000 \times g$ for $10 \mathrm{~min}$ and the pellet was designated the 'mitochondrial' fraction, whereas the supernatant was centrifuged at $100000 \times g$ for $60 \mathrm{~min}$ at $4^{\circ} \mathrm{C}$ and the resulting supernatant was used for preparation of cytosolic fraction. The mitochondrial and cytosolic fractions were stored at $-80^{\circ} \mathrm{C}$ until experimentation. Protein assay was performed by Dc protein assay (Bio-Rad, Hercules, CA, USA).

Mitochondrial isolation, swelling test and detection of cytochrome $c$ release. RLM were isolated by conventional differential centrifugation from the livers of male adult Sprague-Dawley rats fasted overnight. ${ }^{38}$ The isolation buffer consisted of mannitol $(220 \mathrm{mM})$, sucrose $(70 \mathrm{mM})$, Hepes (2 mM), EGTA $(0.5 \mathrm{mM})$ and bovine serum albumin $(0.1 \%), \mathrm{pH} 7.4$. Isolated RLM were suspended in storage buffer consisting of $200 \mathrm{mM}$ sucrose and $2 \mathrm{mM}$ HEPES, pH 7.4. Large amplitude swelling was measured by spectrophotometry in a Beckman DU 640 by recording absorbance change at $540 \mathrm{~nm}$ in incubation buffer consisting of $200 \mathrm{mM}$ sucrose, $20 \mu \mathrm{M} \mathrm{EGTA}, 5 \mathrm{mM}$ succinate, $2 \mu \mathrm{M}$ rotenone, $1 \mu \mathrm{g} /$ $\mathrm{ml}$ oligomycin, $20 \mathrm{mM}$ Tris, $20 \mathrm{mM}$ HEPES and $1 \mathrm{mM} \mathrm{KH}_{2} \mathrm{PO}_{4}$, pH 7.2. To measure cytochrome $c$ release from RLM induced by different additions, RLM $(0.5 \mathrm{mg} / \mathrm{ml})$ in storage buffer were incubated with $\mathrm{Ca}^{2+}(625 \mu \mathrm{M}) \pm \mathrm{CsA}(50 \mu \mathrm{M})$ or DIG $(100 \mathrm{pmol} / \mathrm{mg}$ protein) for $10 \mathrm{~min}$, then the incubated RLM were centrifuged at $10000 \times g$ for $10 \mathrm{~min}$ at $4^{\circ} \mathrm{C}$. The supernatant fractions were further spun at $100000 \times g$ for $15 \mathrm{~min}$ at $4^{\circ} \mathrm{C}$ to eliminate mitochondrial membrane fragments and the resulting supernatants were used to determine cytochrome $c$ released from RLM.

Mitochondrial oxygen consumption. Oxygen consumption was measured with a Clark oxygen electrode (Oxygraph Model 5300: Yellow Spring Instrument Co., Yellow Spring, $\mathrm{OH}, \mathrm{USA})$ as described previously. ${ }^{39}$ Oxygen consumption was monitored in $150 \mathrm{mM}$ sucrose, $5 \mathrm{mM} \mathrm{MgCl}, 5 \mathrm{mM}$ succinate, $1 \mu \mathrm{M}$, rotenone and $10 \mathrm{mM} \mathrm{NaPi}$ buffer, $\mathrm{pH}$ 7.4. Respiratory control ratios (RCR) were calculated after addition of $200 \mu \mathrm{M}$ ADP to initiate state 3 respirations.

Immunoblotting. Proteins were separated by electrophoresis on $14 \%$ SDSPAGE gels and transferred to nitrocellulose membrane. Protein concentration was determined using Bio-Rad Dc protein assay. Rabbit polyclonal anti-Bax (N20) antibody was purchased from Santa Cruz Biotechnology (Santa Cruz, CA, USA) whereas rabbit polyclonal anti-Cyp-D antibody was from Calbiochem (San Diego, CA, USA). Mouse monoclonal anti-cytochrome $c$, anti- $\beta$ actin and anti-MnSOD antibodies were from BD Biosciences, Pharmingen (San Diego, CA, USA). The secondary antibodies used were goat anti-rabbit and goat anti-mouse horseradish peroxidase-conjugated antibodies, respectively, and they were purchased from $B D$ Biosciences, Pharmingen (San Diego, CA, USA). Chemiluminescence detection was performed using ECL detection kit according to the manufacturer's instructions (Pierce, USA).

Bax and Cyp-D gene silencing with siRNAs. Gene silencing with siRNAs (sense and antisense strands) were purchased from 1st base, Britain. The sense strand sequences were: control, 5'-UUCUCCGAACGUGUCACGU (dTdT)-3'; Bax, 5'-GGUGCCGGAACUGAUCAGA(dTdT)-3' and Cyp-D, $5^{\prime}$-CCUGCUAAAUUGUGCGUUA(dTdT)-3'. Cells were transfected with siRNAs using lipofectamine 2000 (Invitrogen, CA, USA) according to the manufacturer's instructions for $48 \mathrm{~h}$ unless otherwise stated. Following transfection, cells were harvested for experiments as described for parental CEM cells.

Statistical analysis. Data were expressed as standard error of the mean (S.E.) of three or more separate experiments performed in duplicate. ANOVA was used for significance testing $(P<0.05)$.
Acknowledgements. This work was supported by Academic Research Fund Grant R183000103112 (to JSA), National Medical Research Council Grant R-183000-177-213 (JSA).

1. Boyce M, Yuan J. Cellular response to endoplasmic reticulum stress: a matter of life or death. Cell Death Differ 2006; 13: 363-373.

2. Yamaguchi $H$, Bhalla $K$, Wang $H G$. Bax plays a pivotal role in thapsigargin-induced apoptosis of human colon cancer HCT116 cells by controlling Smac/Diablo and Omi/HtrA2 release from mitochondria. Cancer Res 2003; 63: 1483-1489.

3. Yamaguchi $\mathrm{H}$, Wang HG. CHOP is involved in endoplasmic reticulum stress-induced apoptosis by enhancing DR5 expression in human carcinoma cells. J Biol Chem 2004; 279: 45495-45502.

4. Roucou X, Montessuit S, Antonsson B, Martinou JC. Bax oligomerization in mitochondrial membranes requires tBid (caspase-8-cleaved Bid) and a mitochondrial protein. Biochem $J$ 2002; 368: 915-921.

5. Korsmeyer SJ, Wei MC, Saito M, Weiler S, Oh KJ, Schlesinger PH. Pro-apoptotic cascade activates BID, which oligomerizes BAK or BAX into pores that result in the release of cytochrome c. Cell Death Differ 2000; 7: 1166-1173.

6. Scorrano L, Korsemeyer SJ. Mechanism of cytochrome $c$ release by proapoptotic BCL-2 family members. Biochem Biophys Res Commun 2003; 304: 437-444.

7. Nechushtan A, Smith CL, Hsu YT, Youle RJ. Conformation of the Bax C-terminal region regulates subcellular location and cell death. EMBO J 1999; 18: 2330-2341.

8. Jürgensmeier JM, Xie Z, Deveraux Q, Ellerby L, Bredesen D, Reed JC. Bax directly induces release of cytochrome c from isolated mitochondria. Proc Natl Acad Sci USA 1998; 95: 4997-5002.

9. Antonsson B, Montessuit S, Lauper S, Eskes R, Martinou JC. Bax oligomerization is required for channel-forming activity in liposomes and to trigger cytochrome $c$ release from mitochondria. Biochem J 2000; 345: 271-278.

10. Iverson SL, Orrenius S. The cardiolipin-cytochrome $c$ interaction and the mitochondrial regulation of apoptosis. Arch Biochem Biophys 2004; 423: 37-46.

11. Orrenius S, Zhivotovsky B. Cardiolipin oxidation sets cytochrome $c$ free. Nat Chem Biol 2005; 1: 188-189.

12. Scorrano L, Ashiya M, Buttle K, Weiler S, Oakes SA, Mannella CA et al. A distinct pathway remodels mitochondrial cristae and mobilizes cytochrome $c$ during apoptosis. Dev Cell 2002; 2: 55-67.

13. Kim TH, Zhao Y, Ding WX, Shin JN, He X, Seo YW et al. Bid-cardiolipin interaction at mitochondrial contact site contributes to mitochondrial cristae reorganization and cytochrome $c$ release. Mol Biol Cell 2004; 15: 3061-3072.

14. Yang JC, Cortopassi GA. Induction of the mitochondrial permeability transition causes release of the apoptogenic factor cytochrome c. Free Radic Biol Med 1998; 24: 624-631.

15. Bradham CA, Qian T, Streetz K, Trautwein C, Brenner DA, Lemasters JJ. The mitochondrial permeability transition is required for tumor necrosis factor alpha-mediated apoptosis and cytochrome $c$ release. Mol Cell Biol 1998; 18: 6353-6364.

16. Nakagawa T, Shimizu S, Watanabe T, Yamaguchi O, Otsu K, Yamagata $\mathrm{H}$ et al. Cyclophilin D-dependent mitochondrial permeability transition regulates some necrotic but not apoptotic cell death. Nature 2005; 434: 652-658.

17. Baines CP, Kaiser RA, Purcell NH, Blair NS, Osinska H, Hambleton MA et al. Loss of cyclophilin $D$ reveals a critical role for mitochondrial permeability transition in cell death. Nature 2005; 434: 658-662.

18. Narita M, Shimizu S, Ito T, Chittenden T, Lutz RJ, Matsuda $\mathrm{H}$ et al. Bax interacts with the permeability transition pore to induce permeability transition and cytochrome $c$ release in isolated mitochondria. Proc Natl Acad Sci USA 1998; 95: 14681-14686.

19. Marzo I, Brenner C, Zamzami N, Jurgensmeier JM, Susin SA, Vieira HL et al. Bax and adenine nucleotide translocator cooperate in the mitochondrial control of apoptosis. Science 1998; 281: 2027-2031.

20. Zamzami N, El Hamel C, Maisse C, Brenner C, Munoz-Pinedo C, Belzacq AS et al. Bid acts on the permeability transition pore complex to induce apoptosis. Oncogene 2000; 19 6342-6350.

21. Shimizu S, Ide T, Yanagida T, Tsujimoto Y. Electrophysiological study of a novel large pore formed by Bax and the voltage-dependent anion channel that is permeable to cytochrome c. J Biol Chem 2000; 275: 12321-12325.

22. Crabtree GR. Calcium, calcineurin, and the control of transcription. J Biol Chem 2001; 276 2313-2316.

23. Fruman DA, Klee $\mathrm{CB}$, Bierer BE, Burakoff SJ. Calcineurin phosphatase activity in $T$ lymphocytes is inhibited by FK 506 and cyclosporin A. Proc Natl Acad Sci USA 1992; 89: 3686-3690.

24. Moss ML, Palmer RE, Kuzmic P, Dunlap BE, Henzel W, Kofron JL et al. Identification of actin and HSP 70 as cyclosporin A binding proteins by photoaffinity labeling and fluorescence displacement assays. J Biol Chem 1992; 267: 22054-22059.

25. Epand RF, Martinou JC, Fornallaz-Mulhauser M, Hughes DW, Epand RM. The apoptotic protein tBid promotes leakage by altering membrane curvature. J Biol Chem 2002; 277 32632-32639.

26. Lucken-Ardjomande S, Martinou JC. Newcomers in the process of mitochondria permeabilization. J Cell Sci 2005; 118: 473-483. 
27. De Giorgi F, Lartigue L, Bauer MK, Schubert A, Grimm S, Hanson GT et al. The permeability transition pore signals apoptosis by directing Bax translocation and multimerization. FASEB J 2002; 16: 607-609.

28. He L, Lemasters JJ. Regulated and unregulated mitochondrial permeability transition pores: a new paradigm of pore structure and function? FEBS Lett 2002; 512: 1-7.

29. Kowaltowski AJ, Castilho RF, Vercesi AE. Mitochondrial permeability transition and oxidative stress. FEBS Lett 2001; 495: 12-15.

30. Armstrong JS, Jones DP. Glutathione depletion enforces the mitochondrial permeability transition and causes cell death in Bcl-2 overexpressing HL60 cells. FASEB J 2002; 16 : 1263-1265.

31. Armstrong JS, Yang H, Duan W, Chua Y, Whiteman M. Cytochrome $b c_{1}$ regulates the mitochondrial permeability transition by two distinct pathways. J Biol Chem 2004; 279: 50420-50428.

32. Jungas T, Motta I, Duffieux F, Fanen P, Stoven V, Ojcius DM. Glutathione levels and BAX activation during apoptosis due to oxidative stress in cells expressing wild-type and mutant cystic fibrosis transmembrane conductance regulator. J Biol Chem 2002; 277: 2791227918.
33. Liu Z, Lu H, Shi H, Du Y, Yu J, Gu S et al. PUMA overexpression induces reactive oxygen species generation and proteasome-mediated stathmin degradation in colorectal cancer cells. Cancer Res 2005; 65: 1647-1654

34. Simon HU, Haj-Yehia A, Levi-Schaffer F. Role of reactive oxygen species (ROS) in apoptosis induction. Apoptosis 2000; 5: 415-418.

35. Ott M, Robertson JD, Gogvadze V, Zhivotovsky B, Orrenius S. Cytochrome $c$ release from mitochondria proceeds by a two-step process. Proc Natl Acad Sci USA 2002; 99: 12591263

36. Hajnoczky G, Robb-Gaspers LD, Seitz MB, Thomas AP. Decoding of cytosolic calcium oscillations in the mitochondria. Cell 1995; 82: 415-424.

37. Yang J, Liu X, Bhalla K, Kim CN, Ibrado AM, Cai J et al. Prevention of apoptosis by Bcl-2: release of cytochrome $c$ from mitochondria blocked. Science 1997; 275: 1129-1132.

38. He L, Lemasters JJ. Heat shock suppresses the permeability transition in rat liver mitochondria. J Biol Chem 2003; 278: 16755-16760.

39. Chua YL, Zhang D, Boelsterli U, Moore PK, Whiteman M, Armstrong JS. Oltipraz-induced phase 2 enzyme response conserved in cells lacking mitochondrial DNA. Biochem Biophys Res Commun 2005; 337: 375-381. 